\title{
Microstructural effects on sodium ion conduction properties of grains and grain boundaries of $\mathrm{Na}_{5} \mathrm{YSi}_{4} \mathrm{O}_{12}$-type silicophosphate glass-ceramics
}

\author{
Toshinori OKURA ${ }^{1, \dagger}$, Koji KAWADA ${ }^{1}$ and Kimihiro YAMASHITA ${ }^{1,2,3}$ \\ ${ }^{1}$ Department of Applied Chemistry, School of Advanced Engineering, Kogakuin University, \\ 2665-1 Nakano, Hachioji, Tokyo 192-0015, Japan \\ ${ }^{2}$ Graduate School of Medical and Dental Sciences, Tokyo Medical and Dental University, \\ 1-5-45 Yushima, Bunkyo, Tokyo 113-8501, Japan \\ ${ }^{3}$ Advanced Central Research Organization, Teikyo University, 2-11-1 Kaga, Itabashi, Tokyo 173-8605, Japan
}

\begin{abstract}
We studied the effects of crystallization conditions on the conduction properties of the $\mathrm{Na}_{5} \mathrm{YSi}_{4} \mathrm{O}_{12}$-type sodium ion conducting glass-ceramics. Crystallization process was controlled by varying annealing parameters of nucleation time $(0-200 \mathrm{~h})$ and crystal growth temperature $\left(900-1100{ }^{\circ} \mathrm{C}\right)$. The present results showed that a shorter nucleation time with annealing at $900^{\circ} \mathrm{C}$ for crystal growth gave rise to higher conductivities of $5 \times 10^{-2}$ $\mathrm{S} \mathrm{cm}^{-1}$ at representative temperatures of $300{ }^{\circ} \mathrm{C}$ and $3 \times 10^{-3} \mathrm{~S} \mathrm{~cm}^{-1}$ at $150{ }^{\circ} \mathrm{C}$, respectively. Those results were attributed to the microstructures of glass-ceramics and the conductivities of a whole glass-ceramic were considered to be dominated by those of grains at $300^{\circ} \mathrm{C}$ and, on the other hand, strongly influenced by those of grain boundaries at $150^{\circ} \mathrm{C}$. It was found that the dependence of a whole conductivity on the apparent number of grain boundaries calculated as the ratio of a whole thickness to an average grain diameter was stronger in the measurements at $150{ }^{\circ} \mathrm{C}$ than at $300^{\circ} \mathrm{C}$. Considering the result, we propose the use of largely grained glassceramics for both higher and lower temperature uses.

@2022 The Ceramic Society of Japan. All rights reserved.
\end{abstract}

Key-words : Sodium ion conductor, Glass-ceramics, Microstructural effect, Grain boundary conduction

\section{Introduction}

All solid-state ion batteries (ASSB) are considered as the future key device to provide clean energy for environmental issues. Above all, lithium ion batteries have been the main target for ASSB, however, sodium ion batteries are also desired to realize because of the natural resources much more abundant than lithium-containing minerals. ${ }^{1)}$ Sodium sulfides solid electrolytes have recently gathered much attention as the leading device of sodium ASSB. ${ }^{2), 3)}$ Considering the instability of the sulfides in an oxidizing atmosphere, however, sodium ion conducting oxides are also becoming a current target for sodium ASSB as a next generation device $^{4)-14)}$ in addition to high-temperature uses such as $\mathrm{Na} / \mathrm{S}$ batteries.

The $\beta / \beta^{\prime \prime}$-alumina ${ }^{15)}$ and NASICON ${ }^{16)}$ have been conventionally recognized as the practical $\mathrm{Na}^{+}$conducting oxides with $10^{-1}-10^{-2}$ and $10^{-4}-10^{-5} \mathrm{~S} \mathrm{~cm}^{-1}$ at 300 and $25^{\circ} \mathrm{C}$, respectively, and to date, numerous studies have

Corresponding author: T. Okura; E-mail: okura@cc. kogakuin.ac.jp

$\$$ Preface for this article: Dol http://doi.org/10.2109/jcersj2. 130.P1-1 been carried out on those $\mathrm{Na}^{+}$conducting ceramics. Subsequently to those, rare-earth $(\mathrm{R})$ containing sodium silicates of $\mathrm{Na}_{5} \mathrm{RSi}_{4} \mathrm{O}_{12}$ were discovered as the $\mathrm{Na}^{+}$conducting compound comprised of $\mathrm{SiO}_{4}{ }^{4-}-12$ memberedrings skeleton structure. ${ }^{17)-19)}$ Recently, $\mathrm{Na}_{2} \mathrm{M}_{2} \mathrm{TeO}_{6}$ (M: $\mathrm{Ni}, \mathrm{Co}, \mathrm{Zn}, \mathrm{Mg})^{20)-22)}$ has been found to exhibit fast $\mathrm{Na}^{+}$ ion conductivities of $10^{-2}$ and $10^{-4} \mathrm{~S} \mathrm{~cm}^{-1}$ at the respective temperatures of 300 and $25^{\circ} \mathrm{C}$. All of these are produced as polycrystalline conductors by sintering of compressed powders. Contrastingly, we have developed glassceramic $\mathrm{Na}^{+}$conductors according to $\mathrm{Na}_{5} \mathrm{RSi}_{4} \mathrm{O}_{12}$-based silicophosphates because of tractability of forming, to which the partial replacement of $\mathrm{PO}_{4}{ }^{3-}$ for the $\mathrm{SiO}_{4}{ }^{4-}$ skeleton contributes due to lowering melting point of starting glasses. The production of dense tubes is inevitable for $\mathrm{Na} / \mathrm{S}$ batteries, where glass-making processing can be expected to have an advantage over conventional sintering. ${ }^{5)-7)}$ To date, we have developed the dense glassceramics in the systems of $\mathrm{Na}_{5} \mathrm{RSi}_{4} \mathrm{O}_{12}$ ( $\mathrm{R}$ : various rareearth elements), ${ }^{23)} \quad \mathrm{Na}_{5} \mathrm{YSi}_{4} \mathrm{O}_{12}$-type $\mathrm{Na}_{3+3 x-y} \mathrm{Y}_{1-x} \mathrm{P}_{y^{-}}$ $\mathrm{Si}_{3-y} \mathrm{O}_{9},{ }^{24)-33)} \mathrm{Na}_{5} \mathrm{FeSi}_{4} \mathrm{O}_{12}{ }^{34)}$ and the derivatives $\mathrm{Na}_{5-z^{-}}$ $\mathrm{Fe}_{1-z} \mathrm{M}_{2} \mathrm{Si}_{4} \mathrm{O}_{12}$ (M: Al, Ga, B), ${ }^{35)}$ and $\left.\mathrm{Na}_{5} \mathrm{ZrSi}_{4} \mathrm{O}_{12} \cdot{ }^{34}\right)$

Of those $\mathrm{Na}_{5} \mathrm{YSi}_{4} \mathrm{O}_{12}$ family, the most conductive materials and tractable glass-ceramics with the composi- 
tion of $\mathrm{Na}_{5} \mathrm{YSi}_{4} \mathrm{O}_{12}$-type $\mathrm{Na}_{4} \mathrm{Y}_{0.6} \mathrm{P}_{0.2} \mathrm{Si}_{3.8} \mathrm{O}_{9}$ was taken in this study. The whole conduction properties of glassceramics primarily depend on those of crystallized grains at a higher temperature, whereas the characteristics of grain boundaries have considerable influence on the total conductivities. Because of the high density of more than $98 \%$, a porosity effect was neglected in this study. The microstructure comprising grain and grain boundaries can be controlled through the thermal process of crystallization and grain growth. With the aim at the development of $\mathrm{Na}^{+}$conducting glass-ceramics for both $\mathrm{Na} / \mathrm{S}$ batteries for high- and ASSB for low-temperature uses, the present study focused on the microstructural effects on the conduction properties of glass-ceramic $\mathrm{Na}_{4} \mathrm{Y}_{0.6} \mathrm{P}_{0.2} \mathrm{Si}_{3.8} \mathrm{O}_{9}$ produced under various temperature and time for crystallization and grain growth.

\section{Materials and methods}

\subsection{Glass-making, and -crystallization procedure}

The precursor glasses were produced according to the previous reports. ${ }^{34), 35)}$ For clarity, the summarized procedure was introduced in the following; the starting powders were prepared by mechanical mixture of the reagent-grade powders of anhydrous $\mathrm{Na}_{2} \mathrm{CO}_{3}, \mathrm{Y}_{2} \mathrm{O}_{3}, \mathrm{NH}_{4} \mathrm{H}_{2} \mathrm{PO}_{4}$ and $\mathrm{SiO}_{2}$ according to the chemical formula of $\mathrm{Na}_{4} \mathrm{Y}_{0.6} \mathrm{P}_{0.2^{-}}$ $\mathrm{Si}_{3.8} \mathrm{O}_{9}$, and calcined at $900{ }^{\circ} \mathrm{C}$ for $0.5 \mathrm{~h}$, then melted at $1350^{\circ} \mathrm{C}$ for $1 \mathrm{~h}$. The composition will be referred to as NYPS in the following for convenience. The melts were rapidly poured into a cylindrical graphite with the size of $15 \mathrm{~mm}$ diameter for electrical measurements, followed by annealing at $500{ }^{\circ} \mathrm{C}$ for $3 \mathrm{~h}$ to form precursor glasses. This study focused on the effects of nucleation time $\left(t_{\mathrm{N}}\right)$ and crystallization temperature $\left(T_{\mathrm{CG}}\right)$ on conduction properties, because the microstructural evolution of glass-ceramics depends on both $t_{\mathrm{N}}$ and $T_{\mathrm{CG}}$. The annealing process was carried out under the controlled schedule shown in Fig. 1 according to the previously reported results on differential thermal analyses. ${ }^{34), 35)}$ Precursor glasses were annealed for nucleation at $600{ }^{\circ} \mathrm{C}$ for $6 \mathrm{~h}$, above approximately $50^{\circ} \mathrm{C}$ of the glass transition point, for various $t_{\mathrm{N}}$ of 0 to $200 \mathrm{~h}$, thereafter heated to the temperature of $T_{\mathrm{CG}}$ for crystal

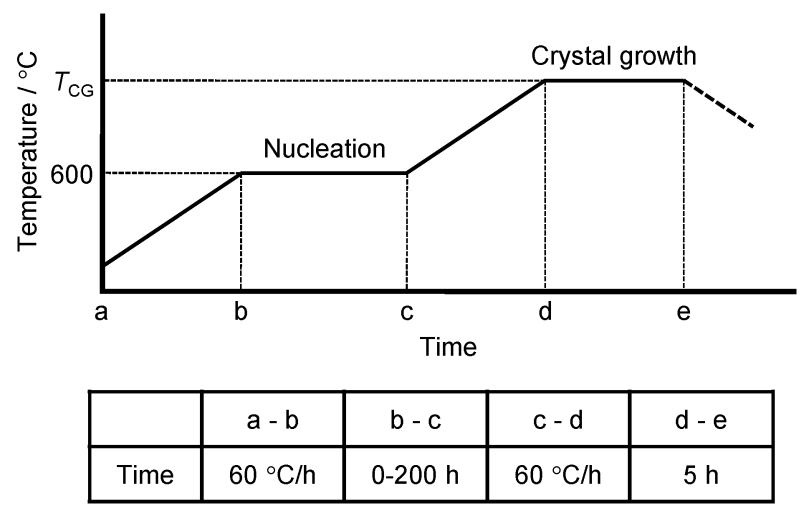

Fig. 1. Heating schedule from room temperature through $600^{\circ} \mathrm{C}$ for nucleation to $T_{\mathrm{CG}}$ for crystal growth with a heating rate of $60^{\circ} \mathrm{C} / \mathrm{h}(\mathrm{a}-\mathrm{b}, \mathrm{c}-\mathrm{d})$ and time of $0-200 \mathrm{~h}(\mathrm{~b}-\mathrm{c})$ and $5 \mathrm{~h}(\mathrm{~d}-\mathrm{e})$. growth, where $T_{\mathrm{CG}}$ was chosen from 900 to $1100^{\circ} \mathrm{C}$ for $5 \mathrm{~h}$, because less conductive precursor phases of $\mathrm{Na}_{3} \mathrm{YSi}_{3} \mathrm{O}_{9}$ and/or $\mathrm{Na}_{9} \mathrm{YSi}_{6} \mathrm{O}_{18}$ appear at lower temperatures than $900{ }^{\circ} \mathrm{C}{ }^{28)}$ Thus obtained glass and glass-ceramic specimens were polished with $0.5 \mu \mathrm{m}$ diamond paste, thereafter subjected to the conductivity measurements.

Identification of the crystalline phases were performed on crushed powders of crystallized specimens by X-ray diffraction (XRD) method. Scanning electron micrographic (SEM) observation was also performed on bulk samples chemically etched with HF solution to evaluate the microstructure and average gran-sizes $(D)$. The apparent densities of glass ceramics were measured by the Archimedes method using kerosene as immersion solution.

\subsection{Electrical measurements}

To evaluate ionic conductivities, the complex impedance measurements were done on cylindrical glasses and glass-ceramics of typically $15 \mathrm{~mm}$ in diameter and $2 \mathrm{~mm}$ in thickness. Thin films of Au were deposited as electrodes on those polished surfaces by rf-magnetron sputtering, and the ac fields ranging from $5 \mathrm{~Hz}$ to $10 \mathrm{MHz}$ in frequency were applied to the glass and glass-ceramic samples for the measurements of conductivities $(\sigma)$ at the temperatures of 150 to $350^{\circ} \mathrm{C}$, because of our limited measuring facility. The complex impedance or admittance loci of glass and glass-ceramics were analyzed by the universal equivalent circuit, ${ }^{32)-35)}$ which was experimentally found to comprise 2 semi-circles in any present glass-ceramic. The two intercepting points of the semi-circles on the real axis are interpreted as the conductance of crystallized grains $\left(\sigma_{\mathrm{G}}\right)$, and the total conductance $\left(\sigma_{\text {Total }}\right)$ of grains and grain boundaries $\left(\sigma_{\mathrm{GB}}\right)$.

\section{Results}

\subsection{Characterization of crystallized glass by XRD and SEM}

As shown in Fig. 2, powder XRD analyses indicated all the observed diffraction peaks marked with solid circles were consistent with those listed in ICDD data, confirming

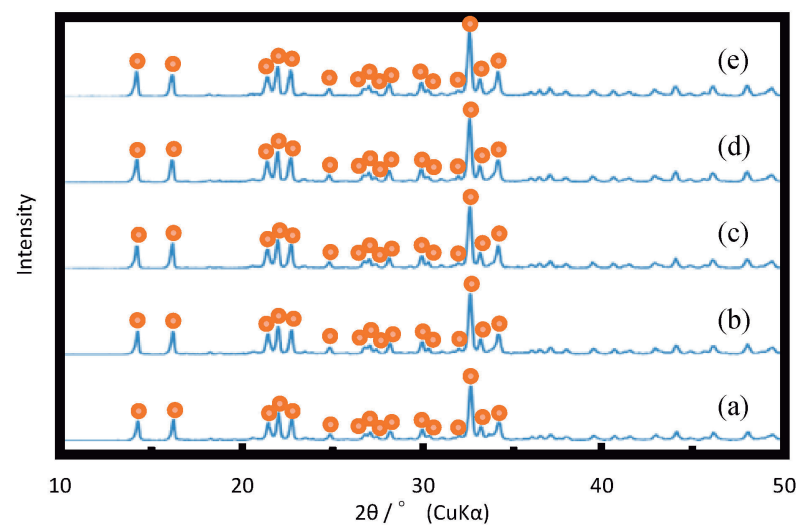

Fig. 2. XRD patterns of glasses crystallized at $900^{\circ} \mathrm{C}$ (a), $950{ }^{\circ} \mathrm{C}(\mathrm{b}), 1000^{\circ} \mathrm{C}(\mathrm{c}), 1050{ }^{\circ} \mathrm{C}(\mathrm{d})$, and $1100{ }^{\circ} \mathrm{C}$ (e), where solid marks correspond to the peaks belonging to $\mathrm{Na}_{5} \mathrm{YSi}_{4} \mathrm{O}_{12}$-type diffraction. 
that all of the glass-ceramic samples crystallized at temperatures $T_{\mathrm{CG}}$ of 900 to $1100^{\circ} \mathrm{C}$ were consisted of $\mathrm{Na}_{5} \mathrm{YSi}_{4} \mathrm{O}_{12}$-type single phase.

All the specimens were confirmed by the Archimedes method to have apparent densities of more than $98 \%$. Scanning electron micrographs shown in Fig. 3 represent the microstructural evolution with $t_{\mathrm{N}}$, and the average grain size $(D)$ varied from ca. 3 to $8 \mu \mathrm{m}$. As the thickness of a glass-ceramic sample was $2 \mathrm{~mm}$, the number of grain boundaries was estimated as $2 \times 10^{3} / D$ to vary from almost $2 \times 10^{2}$ to $7 \times 10^{2}$, depending on $t_{\mathrm{N}}$ and $T_{\mathrm{CG}}$.

\subsection{Dependence of conductivity on crystal growth temperature}

The typical examples of complex admittance diagrams

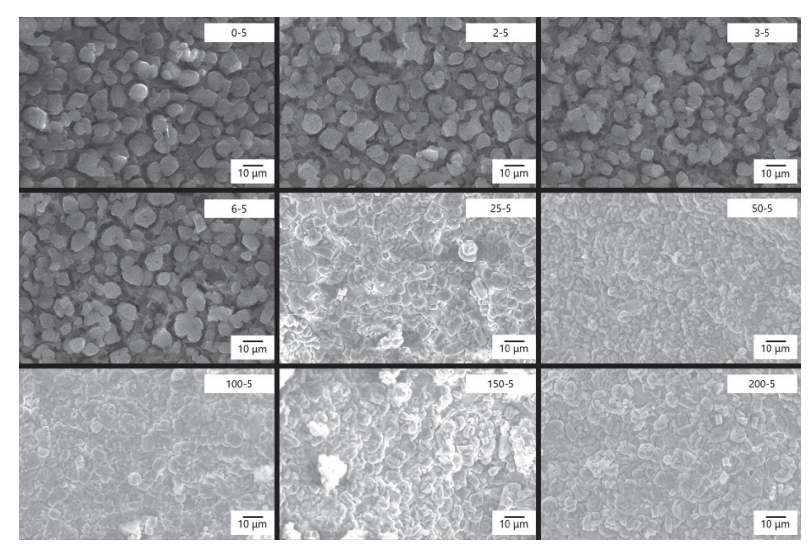

Fig. 3. Scanning electron micrographs of glasses annealed at $600^{\circ} \mathrm{C}$ for various nucleation time $\left(t_{\mathrm{N}}\right)$ and crystallized at $1100^{\circ} \mathrm{C}$ for $5 \mathrm{~h}$, where the inserted figures show the time of $t_{\mathrm{N}}$. of the glass-ceramic NYPS specimens (nucleation at $600{ }^{\circ} \mathrm{C}$ for $\left.6 \mathrm{~h}\right)$ are shown in Figs. 4(a1-a3) and 4(b1-b3). The equivalent circuit according to the previous report ${ }^{36}$ ) was applied to the analysis of those measured admittance diagrams, which consisted of two semi-circles at all the measuring temperatures. Using the two intercepting points of $Y_{1}$ and $Y_{2}$ on the real axis, the conductivities through grains $\left(\sigma_{\mathrm{G}}\right)$ and grain boundaries $\left(\sigma_{\mathrm{GB}}\right)$, and the total conductivity of a sample $\left(\sigma_{\text {Total }}\right)$ with the dimension of $\mathrm{S} \mathrm{cm}^{-1}$ were calculated using the geometrical parameters of a surface area $\left(S=1.5 \mathrm{~cm}^{2}\right)$ and a thickness $(L=0.2 \mathrm{~cm})$ as follows:

$$
\begin{gathered}
\sigma_{\text {Total }}=k Y_{1}, \sigma_{\mathrm{G}}=k Y_{2}, \sigma_{\mathrm{GB}}=k Y_{1} Y_{2} /\left(Y_{2}-Y_{1}\right), \\
\text { where } k=S / L=7.5 \mathrm{~cm} .
\end{gathered}
$$

Because of the complexity of grain boundary geometry, the same geometrical factor $k=7.5 \mathrm{~cm}$ was conveniently employed for the calculation of all of $\sigma_{\mathrm{Total}}, \sigma_{\mathrm{G}}$, and $\sigma_{\mathrm{GB}}$. Using the temperature dependence of those conductivities, the activation energies $(E)$ of sodium ion conduction were calculated from the Arrhenius plots for the total $\left(E_{\text {Total }}\right)$, grains $\left(E_{\mathrm{G}}\right)$ and grain boundaries $\left(E_{\mathrm{GB}}\right)$. As seen from the figures, the difference between $Y_{2}$ and $Y_{1}$ became much smaller at $300^{\circ} \mathrm{C}$ [Figs. $4(\mathrm{a} 3)$ and $4(\mathrm{~b} 3)$ ] than $150{ }^{\circ} \mathrm{C}$ [Figs. 4(a2) and 4(b2)] in both samples crystallized at $T_{\mathrm{CG}}$ of 900 and $1100^{\circ} \mathrm{C}$. The effect of the temperature $T_{\mathrm{CG}}$ (nucleation at $600^{\circ} \mathrm{C}$ for $6 \mathrm{~h}$ ) on the conductivities measured at $300{ }^{\circ} \mathrm{C}$ are shown in Fig. 5, indicating $\sigma_{\mathrm{G}} \cong \sigma_{\text {Total }}$ ranging from $1.5 \times 10^{-2}$ to $2.5 \times 10^{-2} \mathrm{~S} \mathrm{~cm}^{-1}$ with almost constant $E_{\mathrm{G}}$ and $E_{\mathrm{Total}}$ of ca. 30 and $35 \mathrm{~kJ} \mathrm{~mol}^{-1}$, respectively, independently of $T_{\mathrm{CG}}$, and the apparent values of $\sigma_{\mathrm{GB}}$ were between $2.8 \times 10^{-1}$ and $0.8 \times 10^{-1} \mathrm{~S} \mathrm{~cm}^{-1}$ with
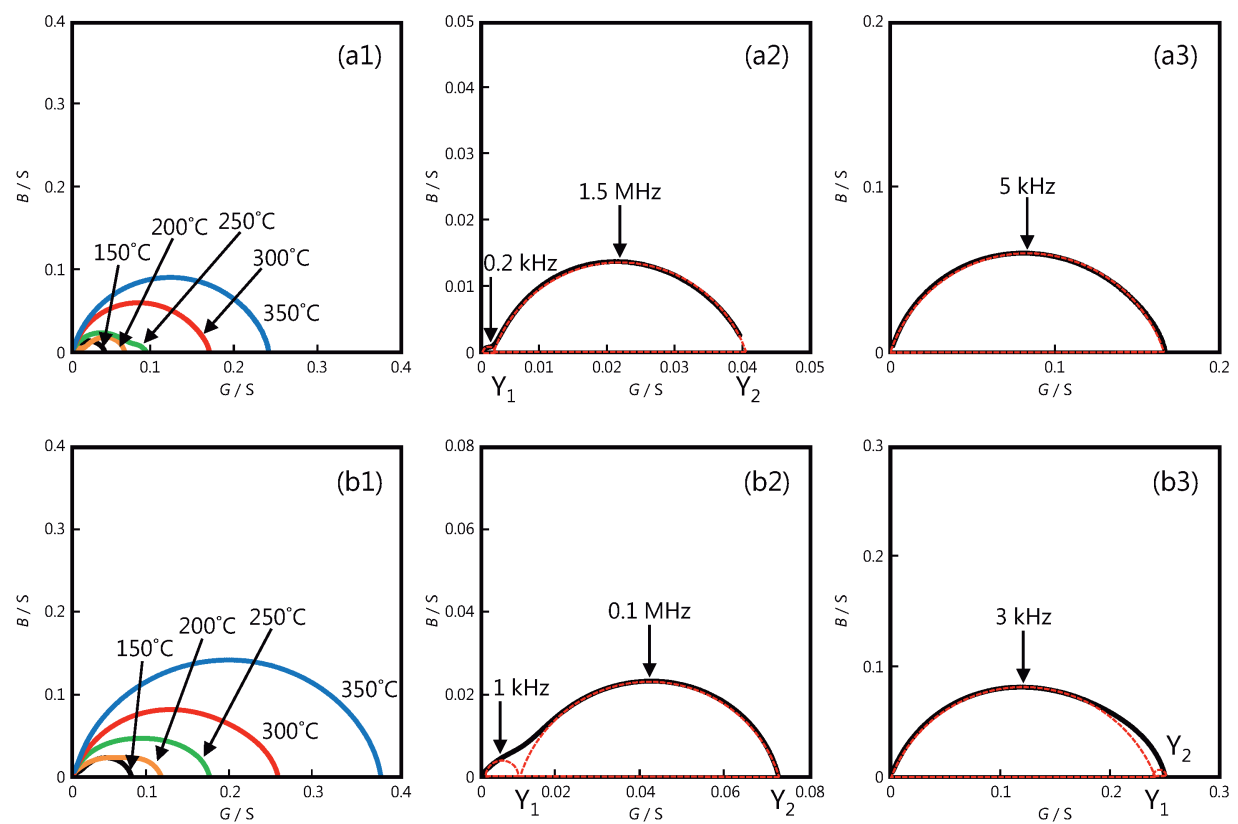

Fig. 4. Complex admittances of glass-ceramics crystallized at $900{ }^{\circ} \mathrm{C}$ (a1) and $1100{ }^{\circ} \mathrm{C}$ (b1) (nucleation at $600^{\circ} \mathrm{C}$ for $6 \mathrm{~h}$ ) measured at temperatures from 150 to $350^{\circ} \mathrm{C}$, where the results obtained at $150{ }^{\circ} \mathrm{C}(\mathrm{a} 2, \mathrm{~b} 2)$ and $300^{\circ} \mathrm{C}(\mathrm{a} 3, \mathrm{~b} 3)$ are shown as typical examples for comparison. The symbols $Y_{1}$ and $Y_{2}$ represent the intercepting points of the two admittance arcs on the real axis, corresponding to the total conductivity of a sample $\left(\sigma_{\text {Total }}\right)$ and the conductivity through grains $\left(\sigma_{\mathrm{G}}\right)$, respectively. 
$E_{\mathrm{GB}}$ varying from 36 to $100 \mathrm{~kJ} \mathrm{~mol}^{-1}$ with increasing $T_{\mathrm{CG}}$. It is noted here that higher values of $\sigma_{\mathrm{GB}}$ arose from the use of the apparent value of $k$ for grain boundary geometry, and the actual one should be much larger than 7.5 because of almost numerous $S$ against extremely small $L$.

As the highest $\sigma_{\text {Total }}$ was obtained at $T_{\mathrm{CG}}$ of $900^{\circ} \mathrm{C}$, the effect of nucleation time $t_{\mathrm{N}}$ was evaluated at $T_{\mathrm{CG}}$ of $900^{\circ} \mathrm{C}$, where $t_{\mathrm{N}}$ was changed from 0 to $200 \mathrm{~h}$. Some examples of the obtained conductivities are shown in the Arrhenius plots (Fig. 6) for $t_{\mathrm{N}}=0$ (a), 6 (b), 50 (c), and $200 \mathrm{~h}$ (d), indicating that the lines of $\sigma_{\mathrm{G}}$ and $\sigma_{\mathrm{GB}}$ crossed each other and the intersecting points went up to higher temperatures with increasing $t_{\mathrm{N}}$.

To investigate the effect of $t_{\mathrm{N}}$ on conduction properties, the demonstrative examples of $\sigma$ obtained at high $\left(300^{\circ} \mathrm{C}\right)$ and low temperatures $\left(150^{\circ} \mathrm{C}\right)$ with $E$ are summarized in Figs. 7(a) $-7(d)$. The value of a whole conductivity $\sigma_{\text {Total }}$ at $300^{\circ} \mathrm{C}$ varied from $5 \times 10^{-2}$ down to $0.8 \times 10^{-2} \mathrm{~S} \mathrm{~cm}^{-1}$ with increasing $t_{\mathrm{N}}$ [Fig. 7(a)]. The similar tendency was

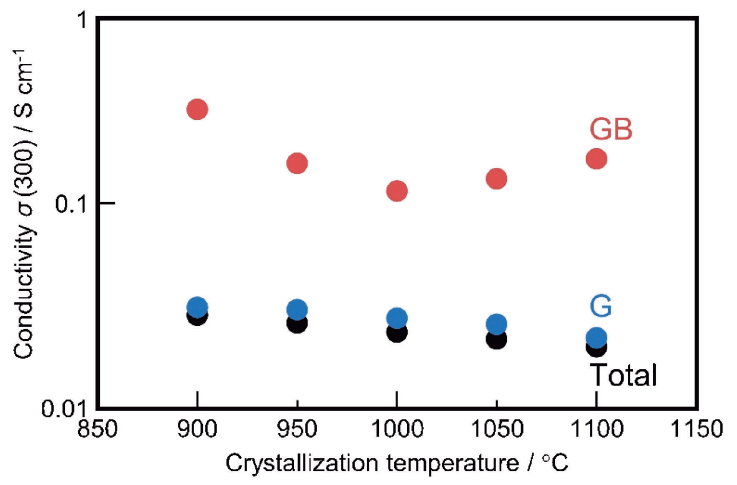

Fig. 5. Dependence of conductivities at $300^{\circ} \mathrm{C}$ of grains $(\mathrm{G})$, grain boundaries (GB), and the total (Total) on crystallization temperature (nucleation at $600^{\circ} \mathrm{C}$ for $6 \mathrm{~h}$ ). observed in the dependence of $\sigma_{\mathrm{G}}$ on $t_{\mathrm{N}}$ [Fig. 7(b)], because the relation of $\sigma_{\mathrm{G}} \cong \sigma_{\text {Total }}$ holds at higher temperatures, as was mentioned above. To the contrary, the values of $\sigma_{\text {Total }}$ at $150^{\circ} \mathrm{C}$ varied within the limited range of $10^{2}$ $\mathrm{S} \mathrm{cm}^{-1}$ from $3 \times 10^{-3}$ down to $2 \times 10^{-5} \mathrm{~S} \mathrm{~cm}^{-1}$ with increasing $t_{\mathrm{N}}$ [Fig. 7(a)], while $\sigma_{\mathrm{G}}$ at $150^{\circ} \mathrm{C}$ varied within the narrow-limited range of $1 \times 10^{-2}$ down to $4 \times 10^{-3}$ $\mathrm{S} \mathrm{cm}^{-1}$ with increasing $t_{\mathrm{N}}$ [Fig. 7(b)]. On the other hand, the values of $\sigma_{\mathrm{GB}}$ both at 300 and $150{ }^{\circ} \mathrm{C}$ drastically decreased between $t_{\mathrm{N}}=2$ and $50 \mathrm{~h}$ and then gradually reached to almost constant [Fig. 7(c)]. The change of $\sigma_{\mathrm{GB}}$ at $150{ }^{\circ} \mathrm{C}$ was scattering in the range of $10^{3} \mathrm{~S} \mathrm{~cm}^{-1}$, more largely than that of $\sigma_{\mathrm{GB}}$ at $300^{\circ} \mathrm{C}$. The conduction activation energies $(E)$ for grains were almost constant as (a)

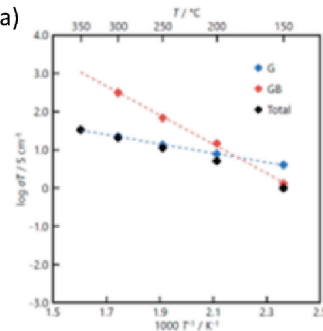

(c)

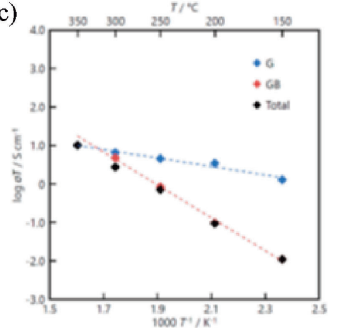

(b)

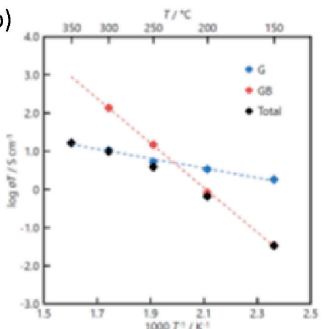

(d)

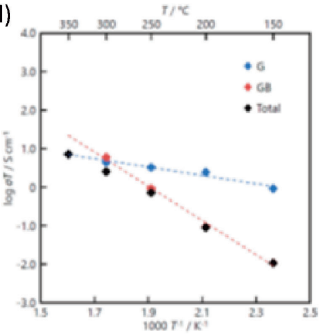

Fig. 6. Arrhenius plots of glass-ceramics nucleated at $600{ }^{\circ} \mathrm{C}$ for $0 \mathrm{~h}$ (a), $6 \mathrm{~h} \mathrm{(b),} 50 \mathrm{~h}$ (c), and $200 \mathrm{~h}(\mathrm{~d})$, thereafter crystallized at $1100^{\circ} \mathrm{C}$ for $6 \mathrm{~h}$.
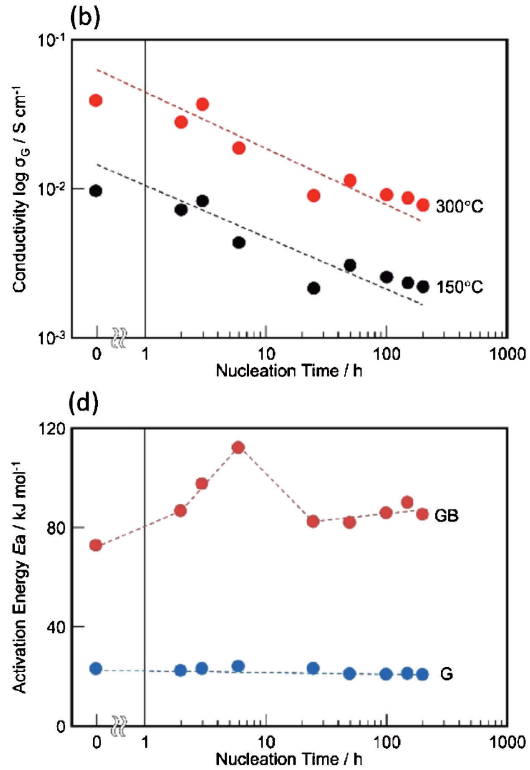

Fig. 7. Nucleation time $\left(t_{\mathrm{N}}\right)$ dependence of conductivities of the total $\left(\sigma_{\text {Total }}\right)(\mathrm{a})$, grains $\left(\sigma_{\mathrm{G}}\right)(\mathrm{b})$, grain boundaries $\left(\sigma_{\mathrm{GB}}\right)(\mathrm{c})$, obtained at 150 and $300^{\circ} \mathrm{C}$, and the activation energies $(E)$ of grains $(\mathrm{G})$ and grain boundaries (GB) (d). The glass-ceramic specimens were prepared by crystallization of nucleated glasses at $1100^{\circ} \mathrm{C}$ for $6 \mathrm{~h}$. 
$36 \mathrm{~kJ} \mathrm{~mol}^{-1}$, whereas those for grain boundaries were scattered between 70 and $110 \mathrm{~kJ} \mathrm{~mol}^{-1}$ [Fig. 7(d)], consistent with previously reported values of silicophosphate glass-ceramics. ${ }^{28)}$ The higher values of $E$ for grain boundaries than those for grains indicate the inferiority of the conduction through grain boundaries in comparison with that through grains.

\section{Discussion}

According to the previous studies on glass-ceramic engineering, annealing time $\left(t_{\mathrm{N}}\right)$ long enough for homogeneous nucleation generally results in small grained polycrystalline, whereas shorter $t_{\mathrm{N}}$ gives largely grained ones after heating at a temperature for crystal growth $\left(T_{\mathrm{CG}}\right){ }^{37)-39)}$ The developed microstructures of crystallized glasses are schematically depicted for comparison with each other in Fig. 8, indicating that crystallized grains grow larger in a glass with fewer nuclei than those in a densely nucleated glass. As mentioned above, the grain-sizes $(D)$ of glass ceramic samples were ranging from 8 down to $3 \mu \mathrm{m}$ with increasing $t_{\mathrm{N}}$, and as the common thickness of glassceramic samples were fixed as $2 \mathrm{~mm}$, the apparent number of grain boundaries $\left(n_{\mathrm{GB}}\right)$ can be estimated as $n_{\mathrm{GB}}=$ thickness $(\mu \mathrm{m}) /$ grain diameter $(\mu \mathrm{m})=2 \times 10^{3} / D$. The calculated values of $n_{\mathrm{GB}}$ varied from $1.2 \times 10^{2}$ to $3.2 \times 10^{2}$, with which the total conductivities of glass-ceramic samples were plotted against the average values of $D$ (Fig. 9). The figure shows the dependence of $\sigma_{\text {Total }}$ on $n_{\mathrm{GB}}$, expressed as the slope of $\left(\log \sigma_{\text {Total }}\right) / n_{\mathrm{GB}}$, was stronger in the measurements at $150^{\circ} \mathrm{C}$ than at $300^{\circ} \mathrm{C}$, supporting the exclusive role of grain boundaries at lower temperatures in the total conductivity. It is also noted that the slope obtained $\left(\Delta_{1}\right)$ at $150^{\circ} \mathrm{C}$ was rather steeper at $n_{\mathrm{GB}}<220$ than that $\left(\Delta_{2}\right)$ at $250<n_{\mathrm{GB}}$. In case of a uniformly constant conductivity of grain boundaries independent of grain-size, the slopes of $\Delta_{1}$ and $\Delta_{2}$ must be equal to each other, indicating that the property of grain boundaries can be changed in the process of grain growth. To clarify the change, we introduce a parameter of $\alpha$, which is defined as the resistance of a single grain layer $\left(R_{\mathrm{SGB}}\right)$ enclosed with grain

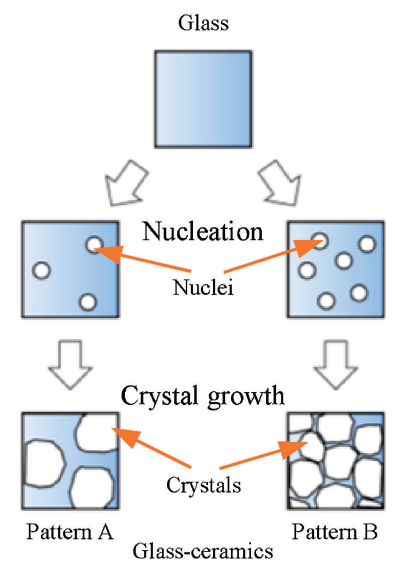

Fig. 8. Schematic microstructural evolution of glass during crystallization, where patterns $\mathrm{A}$ and $\mathrm{B}$ correspond to nucleation treatment for short and long time, respectively. boundaries, since $R_{\mathrm{SGB}} \propto R_{\text {Total }} / n_{\mathrm{GB}}=\left(1 / \sigma_{\text {Total }}\right) \times(L / S) /$ $(L / D)=D /\left(S \times \sigma_{\text {Total }}\right)(\Omega)$. The values of $\alpha$ were summarized in Table 1 and the relationship between $R_{\mathrm{SGB}}$ and $D$ is shown in Fig. 10, where the values of $R_{\mathrm{SGB}}=\left(D / \sigma_{\text {Total }}\right)$ slightly varied within $2 \times 10^{2}$ to $9 \times 10^{2} \Omega$, regardless of $D$ at $300^{\circ} \mathrm{C}$. On the other hand, the values obtained at $150{ }^{\circ} \mathrm{C}$ were almost constant around $1 \times 10^{5}$ to $2 \times 10^{5} \Omega$ for

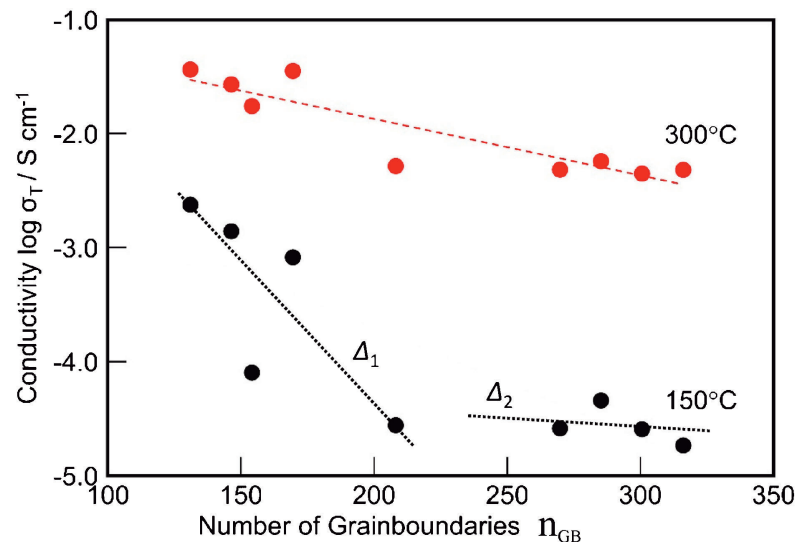

Fig. 9. Dependence of the total conductivities $\left(\sigma_{\text {Total }}\right)$ measured at 150 and $300{ }^{\circ} \mathrm{C}$ on number of grain boundaries $\left(\sigma_{\text {Total }}\right)$ along thickness, where the parameters $\Delta_{1}$ and $\Delta_{2}$ represent the slopes of $\left(\log \sigma_{\text {Total }}\right) / n_{\mathrm{GB}}$, depending on the region of $n_{\mathrm{GB}}$.

Table 1. Effect of nucleation time on grain size $(D)$ and resistivity along a single grain boundary $\left(R_{\mathrm{SGB}}\right)$ measured at 150 and $300^{\circ} \mathrm{C}$

\begin{tabular}{cccc}
\hline \multirow{2}{*}{$\begin{array}{c}\text { Nucleation Time } \\
{[\mathrm{h}]}\end{array}$} & $\begin{array}{c}D \\
{[\mu \mathrm{m}]}\end{array}$ & $150^{\circ} \mathrm{C}$ & $300^{\circ} \mathrm{C}$ \\
\cline { 2 - 4 } & 7.6 & $3 \times 10^{3}$ & $2 \times 10^{2}$ \\
2 & 6.8 & $5 \times 10^{3}$ & $3 \times 10^{2}$ \\
3 & 5.9 & $7 \times 10^{3}$ & $2 \times 10^{2}$ \\
6 & 6.5 & $8 \times 10^{4}$ & $4 \times 10^{2}$ \\
25 & 3.5 & $8 \times 10^{4}$ & $6 \times 10^{2}$ \\
50 & 3.7 & $1 \times 10^{5}$ & $8 \times 10^{2}$ \\
100 & 4.8 & $2 \times 10^{5}$ & $9 \times 10^{2}$ \\
150 & 3.2 & $2 \times 10^{5}$ & $7 \times 10^{2}$ \\
200 & 3.3 & $1 \times 10^{5}$ & $7 \times 10^{2}$ \\
\hline
\end{tabular}

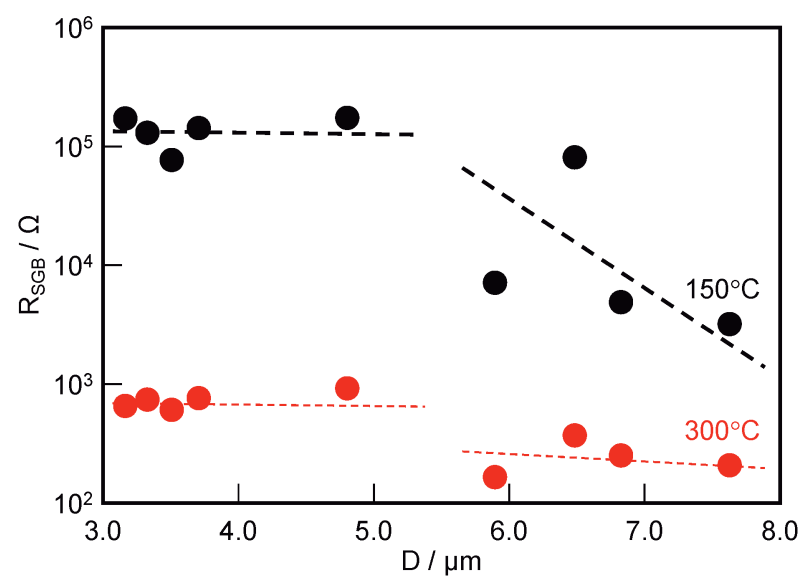

Fig. 10. Dependence of resistivity along a single grain boundary $\left(R_{\mathrm{SGB}}\right)$ measured at 150 and $300^{\circ} \mathrm{C}$ on grain size. 
$D<5 \mu \mathrm{m}$, whereas those were scattered roughly between $3 \times 10^{3}$ to $8 \times 10^{4} \Omega$ for $5 \mu \mathrm{m}<D$. Those results indicate the crystallinity, volume, or composition of grain boundaries can change during grain growth depending on the initial size and density of nuclei, in spite of the annealing for crystallization at the same temperature of $900{ }^{\circ} \mathrm{C}$. As mentioned above (Fig. 8), the short-time annealing for nucleation gave rise to larger grained glass-ceramics after crystallization. The depicted figure also suggests that grain boundaries might be promoted to crystallize in a densely nucleated glass because the homogeneous structure. Control of annealing schedule of glasses can be said to be important for the preparation of conductive glass-ceramics at lower temperature.

\section{Conclusion}

We have studied the effects of annealing conditions of nucleation time $(0-200 \mathrm{~h})$ and crystal growth temperature $\left(900-1100^{\circ} \mathrm{C}\right)$ on the conductivity of $\mathrm{Na}_{5} \mathrm{RSi}_{4} \mathrm{O}_{12}$-type $\mathrm{Na}^{+}$ion conducting glass-ceramics. A shorter nucleation time with annealing at $900^{\circ} \mathrm{C}$ for crystal growth gave rise to the highest conductivities of $5 \times 10^{-2} \mathrm{~S} \mathrm{~cm}^{-1}$ at $300^{\circ} \mathrm{C}$ and $3 \times 10^{-3} \mathrm{~S} \mathrm{~cm}^{-1}$ at $150^{\circ} \mathrm{C}$, respectively. The results were attributed to the fact that the conductivities of a whole glass-ceramic were dominated by those of grains at high temperatures such as $300^{\circ} \mathrm{C}$ and, on the other hand, strongly influenced by those of grain boundaries at lower temperature of $150^{\circ} \mathrm{C}$.

Based on the present results, the annealing conditions of time and temperature should be appropriately chosen for the high- and low-temperature uses such as sodium/sulfurand all-solid state-secondary batteries.

\section{References}

1) A. Hayashi, K. Noi, A. Sakuda and M. Tatsumisago, Nat. Commun., 3, 1-5 (2012).

2) M. Tatsumisago and A. Hayashi, Int. J. Appl. Glass Sci., 5, 226-235 (2014).

3) N. Tanibata, M. Deguchi, A. Hayashi and M. Tatsumisago, Chem. Mater., 29, 5232-5238 (2017).

4) K. Noi, Y. Nagata, T. Hakari, K. Suzuki, S. Yabuchi, Y. Ito, A. Sakuda, A. Hayashi and M. Tatsumisago, $A C S$ Appl. Mater. Inter., 10, 19605-19614 (2018).

5) T. Honma, T. Togashi, N. Ito and T. Komatsu, Ceram. Eng. Sci. Proc., 34, 33-40 (2013).

6) T. Honma, A. Sato, N. Ito, T. Togashi, K. Shinozaki and T. Komatsu, J. Non-Cryst. Solids, 404, 26-31 (2014).

7) T. Honma, M. Okamoto, T. Togashi, N. Ito, K. Shinozaki and T. Komatsu, Solid State Ionics, 269, 19-23 (2015).

8) H. Wang, K. Okubo, M. Inada, G. Hasegawa, N. Enomoto and K. Hayashi, Solid State Ionics, 322, 5460 (2018).

9) Y. Uchida, G. Hasegawa, K. Shima, M. Inada, N. Enomoto, H. Akamatsu and K. Hayashi, ACS Appl. Energy Mater., 2, 2913-2920 (2019).

10) H. Yamauchi, J. Ikejiri, F. Sato, H. Oshita, T. Honma and T. Komatsu, J. Am. Ceram. Soc., 102, 6658-6667 (2019).

11) S. Komaba, N. Yabuuchi, T. Nakayama, A. Ogata, T. Ishikawa and I. Nakai, Inorg. Chem., 1, 6211-6220 (2012).

12) N. Yabuuchi, K. Kubota, M. Dahbi and S. Komaba, Chem. Rev., 1, 11636-11682 (2014).

13) N. Yabuuchi, I. Ikeuchi, K. Kubota and S. Komaba, ACS Appl. Mater. Inter., 8, 32292-32299 (2016).

14) M. Tanabe, T. Honma and T. Komatsu, J. Asian Ceram. Soc., 5, 209-215 (2017).

15) C. R. Peters, M. Bettman, J. W. Moore and M. D. Glick, Acta Crystallogr. B, 27, 1826-1834 (1971).

16) H. Y.-P. Hong, Mater. Res. Bull., 11, 173-182 (1976).

17) J. B. Goodenough, H. Y.-P. Hong and J. A. Kafalas, Mater. Res. Bull., 11, 203-220 (1976).

18) R. D. Shannon, B. E. Taylor, T. E. Gier, H. Y. Chen and T. Berzins, Inorg. Chem., 17, 958-964 (1978).

19) H. U. Beyeler and T. Hibma, Solid State Commun., 27, 641-643 (1978).

20) M. A. Evstigneeva, V. B. Nalbandyan, A. A. Petrenko, B. S. Medvedev and A. A. Kataev, Chem. Mater., 23 , 1174-1181 (2011).

21) J. Wua, Z. Yu, Q. Wang and X. Guo, Energy Stor. Mater., 24, 467-471 (2020).

22) X. Li, F. Bianchini, J. Wind, C. Pettersen, D. S. Wragg, P. Vajeeston and H. Fjellva, ACS Appl. Mater. Inter., 12, 28188-28198 (2020).

23) T. Okura, T. Takahashi, H. Monma and K. Yamashita, Solid State Ionics, 179, 1291-1295 (2008).

24) K. Yamashita, T. Nojiri, T. Umegaki and T. Kanazawa, Solid State Ionics, 35, 299-306 (1989).

25) K. Yamashita, T. Nojiri, T. Umegaki and T. Kanazawa, Solid State Ionics, 40-41, 48-52 (1990).

26) K. Yamashita, S. Okura, T. Umegaki and T. Kanazawa, Solid State Ionics, 26, 279-286 (1988).

27) K. Yamashita, S. Ohkura, T. Umegaki and T. Kanazawa, J. Ceram. Soc. Jpn., 96, 967-972 (1988).

28) K. Yamashita, T. Umegaki, M. Tanaka, T. Kakuta and T. Nojiri, J. Electrochem. Soc., 143, 2180-2186 (1996).

29) K. Yamashita, M. Matsuda and T. Umegaki, J. Mater. Res., 13, 3361-3364 (1998).

30) T. Okura, M. Tanaka, H. Kanzawa and G. Sudoh, Solid State Ionics, 86-88, 511-516 (1996).

31) K. Yamashita, M. Tanaka, T. Kakuta, M. Matsuda and T. Umegaki, J. Alloy. Compd., 193, 283-285 (1993).

32) T. Okura, K. Kawada, N. Yoshida, H. Monma and K. Yamashita, Solid State Ionics, 225, 367-370 (2012).

33) T. Okura, K. Kawada, N. Yoshida, H. Monma and K. Yamashita, Solid State Ionics, 262, 604-608 (2014).

34) K. Kawada, K. Yamashita and T. Okura, J. Non-Cryst. Solids, 545, 1-9 (2020).

35) K. Kawada, K. Yamashita and T. Okura, J. Ceram. Soc. Jpn., 128, 375-380 (2020).

36) T. Okura, M. Saimaru, H. Monma and K. Yamashita, Solid State Ionics, 180, 537-540 (2009).

37) K. Matusita, T. Komatsu and R. Yokota, J. Mater. Sci., 19, 291-296 (1984).

38) I. W. Donald, J. Mater. Sci., 30, 904-915 (1995).

39) Y. M. Sung, J. Mater. Sci., 31, 5421-5427 (1996). 